\title{
GMR
}

\section{Interleukin-6 -572G/C polymorphism and prostate cancer susceptibility}

\author{
W.J. Huang ${ }^{1,2}$, L.J. Wu ${ }^{2}$, Z.C. $\mathrm{Min}^{2}$, L.T. Xu², C.M. Guo ${ }^{2}$, Z.P. Chen ${ }^{2}$, \\ X.J. $\mathrm{Lou}^{2}$, B. Xu ${ }^{3}$ and B.D. $\mathrm{Lv}^{1,4}$ \\ ${ }^{1}$ Department of Urology, the Second Affiliated Hospital, \\ Zhejiang Chinese Medical University, Hangzhou, China \\ ${ }^{2}$ Department of Urology, Linan People's Hospital, Hangzhou, China \\ ${ }^{3}$ Department of Urology, Zhongda Hospital, Nanjing, China \\ ${ }^{4}$ Andrology Laboratory on Integration of Chinese and Western Medicine, \\ Zhejiang Provincial Key Laboratory of Traditional Chinese Medicine, \\ Hangzhou, China
}

Corresponding author: B.D. Lv

E-mail: Bodonglv0571@163.com

Genet. Mol. Res. 15 (3): gmr.15037563

Received January 5, 2016

Accepted August 2, 2016

Published September 16, 2016

DOI http://dx.doi.org/10.4238/gmr.15037563

Copyright (C) 2016 The Authors. This is an open-access article distributed under the terms of the Creative Commons Attribution ShareAlike (CC BY-SA) 4.0 License.

ABSTRACT. Strong evidence suggests that cancer-associated
inflammation promotes tumor growth and progression, and interleukin- 6
(IL6) is an important modulator of inflammation. However, the roles of
IL6 and mutations of its corresponding gene in prostate cancer have not
been clearly documented. We retrieved data from the Oncomine database
concerning IL6 expression in prostate cancer and its role in prostate-
specific antigen (PSA) recurrence. We also performed a case-control
study of the IL6 -572G/C polymorphism (rs 1800796 ) in 236 sporadic
prostate cancer patients and 256 healthy controls from a southern Han
Chinese population. Odds ratios (ORs) with $95 \%$ confidence intervals
(CIs) were estimated to assess the association between rs 1800796 and 
prostate cancer susceptibility. A dual-luciferase reporter assay was used to test the transcriptional activity of the IL6 promoter $\mathrm{G}$ and $\mathrm{C}$ alleles. IL6 was overexpressed in prostate cancer tissues compared to normal tissues, especially in those with higher Gleason scores. Moreover, elevated IL6 expression was associated with high PSA recurrence rate in Oncomine data. Our case-control study demonstrated that compared with the $-572 \mathrm{C}$ allele, the $-572 \mathrm{G}$ allele conferred a borderline increased risk of prostate cancer $(\mathrm{OR}=1.31,95 \% \mathrm{CI}=0.99-1.74, \mathrm{P}=0.061)$. This was more pronounced in the subgroup of individuals having never smoked $(\mathrm{OR}=1.85,95 \% \mathrm{CI}=1.07-3.22)$. Moreover, the $\mathrm{G}$ allele showed increased activity relative to the $\mathrm{C}$ allele in the dual-luciferase reporter assay. Our results suggest that the $-572 \mathrm{G} / \mathrm{C}$ polymorphism may be associated with $I L 6$ expression, which in turn plays a role in prostate cancer development.

Key words: Interleukin-6; IL6; Polymorphism; Prostate cancer

\section{INTRODUCTION}

Accumulating evidence suggests that inflammation is involved in the development and progression of prostate cancer (Platz and De Marzo, 2004). Several surrogate measures of inflammatory status, such as history of prostatitis (Dennis et al., 2002) and sexually transmitted infections (Dennis and Dawson, 2002), and genetic variation in immune response genes (Sun et al., 2007) have been associated with prostate cancer risk. Moreover, inflammation is frequently observed in prostate tumor specimens and proliferative inflammatory atrophy is often present adjacent to tumor cells and prostatic intraepithelial neoplasia (Schatteman et al., 2000; Gerstenbluth et al., 2002). The degree of inflammation in prostate tumors independently predicts disease aggressiveness in the form of biochemical recurrence (Irani et al., 1999).

Interleukin-6 (ILO), mapped to chromosome 7p21-24, is a key inflammatory mediator of the Th2 response. It encodes a 185-amino acid phosphorylated glycoprotein cytokine involved in various pathophysiological processes, such as inflammation and carcinogenesis, including bone metastasis (Corcoran and Costello, 2003). Increased IL6 levels in prostate cancer are associated with decreased apoptosis, enhanced invasive capacity and angiogenesis via MAPK, STAT3, and PI3K-AKT signaling pathways, and activation of androgen receptors (Cabrespine et al., 2007).

Several common single nucleotide polymorphisms have been identified in the IL6 gene promoter, namely $-597 \mathrm{G} / \mathrm{A},-572 \mathrm{G} / \mathrm{C}$, and $-174 \mathrm{G} / \mathrm{C}$ (Terry et al., 2000). Recently, Gu et al. (2008) reported that only one of these $(-572 \mathrm{G} / \mathrm{C}$, rs 1800796) was identified in a Han Chinese population. Moreover, this polymorphism is associated with IL6 production by leukocytes in response to in vitro lipopolysaccharide stimulation in an allele-dose-dependent manner.

Although several reports exist concerning the association between IL6 sequence variations and prostate cancer, most have concentrated on the $-174 \mathrm{G} / \mathrm{C}$ variant, another functional polymorphism in the promoter of this gene. Since serum IL6 levels are highly increased in prostate cancer patients, and the $-572 \mathrm{G} / \mathrm{C}$ polymorphism affects IL6 transcription and production in vivo, we hypothesized that this variant might affect individual susceptibility to this disease. Hence, we performed a case-control study of 236 prostate cancer patients and 256 healthy controls in a southern Han Chinese population.

Genetics and Molecular Research 15 (3): gmr.15037563 


\section{MATERIAL AND METHODS}

\section{Oncomine database}

Prostate cancer microarray datasets were retrieved from the Oncomine Cancer Profiling Database (www.oncomine.org) to investigate IL6 expression in this disease.

\section{Study subjects}

Subjects in this study were unrelated individuals of similar ethnicity from southern China having visited the Second Affiliated Hospital, Zhejiang Chinese Medical University. To be included in our study, patients $(\mathrm{N}=236)$ had to have histologically confirmed prostate adenocarcinoma, be of similar ethnicity to other patients in this group, and provide their informed consent. Control subjects $(\mathrm{N}=256)$ were frequency-matched individuals with no history of cancer having received a routine checkup, and were recruited over the same period. Controls were excluded if they had an abnormal prostate-specific antigen (PSA) level ( $\geq 4.0$ $\mathrm{ng} / \mathrm{mL}$ ), or abnormal digital rectal examination results.

This study was approved by the Second Affiliated Hospital, Zhejiang Chinese Medical University. Each subject was interviewed personally using a questionnaire regarding age, race, tobacco use, alcohol consumption and family history of cancer. For the present research, smoking was defined as more than five cigarettes per day for more than five years. Pack-years [(cigarettes per day / 20) x (years smoked)] were calculated as an indication of cumulative smoking exposure. Drinking was defined as the consumption of alcohol at least three times per week for more than 10 years. Family history of cancer was defined as cancer in first-degree relatives (parents, siblings, or children). A peripheral blood sample $(2 \mathrm{~mL})$ was collected from patients and controls in ethylenediaminetetraacetic acid-containing vials. For patients, disease stage was determined by pathologic findings, pelvic computed tomography scanning, magnetic resonance imaging, and radionuclide bone scans. Tumor stage was determined using tumornode-metastasis (TNM) classification and graded according to World Health Organization guidelines. Pathologic grade was recorded using Gleason scoring.

\section{Genotyping}

Genomic DNA was extracted from whole blood by the standard proteinase K digestion and phenol/chloroform method (Lee et al., 1998). Polymorphisms were analyzed using the polymerase chain reaction (PCR)-restriction fragment length polymorphism (RFLP) technique. Each PCR comprised $10 \mu \mathrm{L}$, containing 5 ng genomic DNA, 2.5 pmol each primer, $4 \mu \mathrm{L}$ double-distilled $\mathrm{H}_{2} \mathrm{O}$, and $5 \mu \mathrm{L}$ PCR Mix (Nanjing Genetime Biotechnology Co., Nanjing, China). A PTC-200 thermal cycler (Bio-Rad, Hercules, CA, USA) and the following primers were used: 5'- GCC AGG CAG TTC TAC AAC AGG C-3' (forward) and 5'- CCT CTG ACT CCA TCG CAG CC-3' (reverse). For RFLP analysis, PCR products were digested with HaeIII (MBI Fermentas Inc., Waltham, MA, USA) at $37^{\circ} \mathrm{C}$ overnight, then separated on a $3.0 \%$ agarose gel, and subsequently stained with ethidium bromide. Two researchers performed the RFLP procedure and gel analysis. As confirmation, 10\% of samples were retested and consistent results were obtained.

Genetics and Molecular Research 15 (3): gmr.15037563 


\section{Dual-luciferase reporter assay}

IL6 promoter luciferase reporter vectors containing either the $-572 \mathrm{G}$ or $-572 \mathrm{C}$ sequence were prepared by amplifying the IL6 promoter region using the following restriction sitecontaining primers: 5'-GAA GGT ACC ACA GTG GTG AAG AGA CTC AG-3' (forward) and 5'-GGC TCG AGG GCA GAA TGA GCC TCA GAC-3' (reverse) for -572C; 5'-CAA CAG CCC CTC ACA GGG AGA GCC AG-3' (forward) and 5'-TGT GAG GGG CTG TTG TAG AAC TGC CTG G-3' (reverse) for -572G. The fragments were subsequently cloned into a pGL3-Basic vector (Promega, Madison, WI, USA), and after confirmation by sequencing, vectors were transfected into DU145 and PC3 cells. Approximately $10^{6}$ cells were seeded onto 24-well plates and each well was transfected with $1.0 \mu \mathrm{g}$ vector DNA carrying either the $-572 \mathrm{G}$ or $-572 \mathrm{C}$ sequence, and $0.1 \mu \mathrm{g}$ pRL-SV40 control vector. After $48 \mathrm{~h}$ of transfection, cell lysates were harvested and firefly luciferase activity was measured and normalized against that of Renilla luciferase using a dual-luciferase reporter assay (Promega).

\section{Statistical analysis}

Associations between clinicopathologic factors and the IL6 -572G/C polymorphism were assessed by the chi-square test or Fisher exact test. Odds ratios (ORs) and $95 \%$ confidence internals (CIs) were calculated by logistic regression analysis to quantify the association between the IL6 $-572 \mathrm{G} / \mathrm{C}$ polymorphism and risk of prostate cancer, with adjustment for potential covariates [age, body mass index (BMI), cigarette smoking, alcohol drinking, and family history of cancer].

\section{RESULTS}

\section{Expression of IL6 in prostate cancer and its role in PSA recurrence}

As shown in Figure 1, in Taylor's study, expression of IL6 in prostate cancer specimens was significantly increased compared to normal tissues (Figure $1 \mathrm{~A}, \mathrm{P}=0.002$ ). In addition, in Singh's study, higher IL6 levels in prostate cancer tissues were associated with higher Gleason scores (Figure 1B, $\mathrm{P}=0.012$ ). To assess the role of IL6 expression in PSA recurrence, we conducted survival analyses using three studies and found that high levels of IL 6 were related to poorer prognoses (Figure 2).
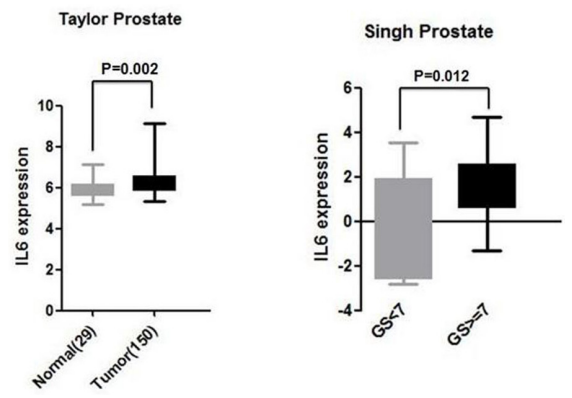

Figure 1. A. Data in the Oncomine cancer database demonstrated differential expression of IL6 in prostate cancer specimens compared with normal tissues in Taylor's study. B. Higher IL6 expression in prostate cancer tissues was associated with higher Gleason score (GS; P = 0.012) in Singh's study.

Genetics and Molecular Research 15 (3): gmr.15037563 

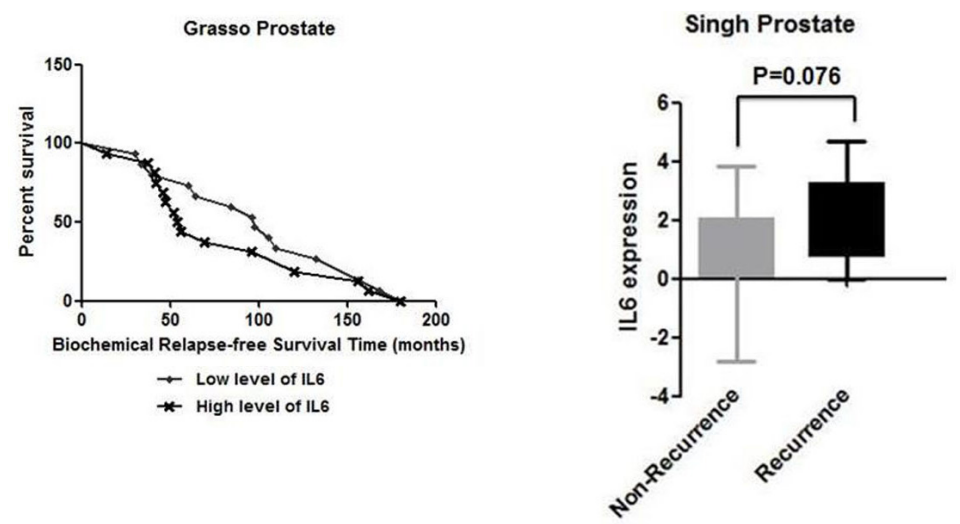

Figure 2. Role of IL6 in predicting biochemical relapse after radical prostatectomy.

\section{Characteristics of the study population}

Demographic and other selected characteristics of the study population are presented in Table 1. Compared with control subjects, prostate cancer patients had higher BMIs $(\mathrm{P}=$ $0.009)$ and were more likely to have a family history of cancer $(P=0.031)$. Cases and controls were similar in terms of age and smoking and drinking status.

Table 1. Demographic characteristics of prostate cancer cases and control subjects.

\begin{tabular}{|c|c|c|c|c|c|}
\hline \multirow[t]{2}{*}{ Characteristic } & \multicolumn{2}{|c|}{ Cases $(\mathrm{N}=236)$} & \multicolumn{2}{|c|}{ Controls $(\mathrm{N}=256)$} & \multirow[t]{2}{*}{$\mathrm{P}$ value $^{\mathrm{a}}$} \\
\hline & $\mathrm{N}$ & $\%$ & $\mathrm{~N}$ & $\%$ & \\
\hline Age (years) & & & & & 0.591 \\
\hline$\leq 70$ & 104 & 44.07 & 119 & 46.48 & \\
\hline$>70$ & 132 & 55.93 & 137 & 53.52 & \\
\hline Body mass index $\left(\mathrm{kg} / \mathrm{m}^{2}\right)$ & & & & & 0.009 \\
\hline$\leq 23$ & 77 & 32.63 & 113 & 44.14 & \\
\hline$>23$ & 159 & 67.37 & 143 & 55.86 & \\
\hline Cigarette smoking (pack-years) & & & & & 0.340 \\
\hline 0 & 96 & 40.68 & 118 & 46.09 & \\
\hline$\leq 20$ & 54 & 22.88 & 60 & 23.44 & \\
\hline$>20$ & 86 & 36.44 & 78 & 30.47 & \\
\hline Alcohol drinking & & & & & 0.069 \\
\hline Never & 130 & 55.08 & 120 & 46.88 & \\
\hline Ever & 106 & 44.92 & 136 & 53.13 & \\
\hline Family history of cancer & & & & & 0.031 \\
\hline No & 179 & 75.85 & 214 & 83.59 & \\
\hline Yes & 57 & 24.15 & 42 & 16.41 & \\
\hline
\end{tabular}

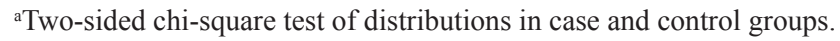

\section{IL6 polymorphism genotype distribution and risk of prostate cancer}

Table 2 shows IL6 -572G/C genotype and allele distributions among cases and controls. Genotype frequencies in the control group were in agreement with Hardy-Weinberg equilibrium (chi-square $=2.80, \mathrm{P}=0.094$ ), suggesting that our results are applicable to the wider population. After adjusting for potential covariates (age, BMI, cigarette smoking, alcohol drinking, and family history of cancer), no significant association was observed between the $-572 \mathrm{G} / \mathrm{C}$ polymorphism and prostate cancer risk.

Genetics and Molecular Research 15 (3): gmr.15037563 
Table 2. Genotypes of prostate cancer patients and control subjects.

\begin{tabular}{|c|c|c|c|c|}
\hline Genotype & Cases [N (\%)] & Controls $^{\mathrm{a}}[\mathrm{N}(\%)]$ & P value ${ }^{b}$ & Adjusted OR $(95 \% \mathrm{CI})^{\mathrm{c}}$ \\
\hline Total & 236 & 256 & & \\
\hline $\mathrm{CC}$ & $117(49.58)$ & $144(56.25)$ & & 1.00 (reference) \\
\hline $\mathrm{GC}$ & $88(37.29)$ & 89 (34.77) & 0.257 & $1.25(0.85-1.86)$ \\
\hline GG & $31(13.14)$ & $23(8.98)$ & 0.130 & $1.60(0.87-2.96)$ \\
\hline \multicolumn{5}{|l|}{ Trend test } \\
\hline $\mathrm{CC}$ & $117(49.58)$ & $144(56.25)$ & \multirow[t]{2}{*}{0.123} & 1.00 (reference) \\
\hline GC/GG & $119(50.42)$ & $112(43.75)$ & & $1.33(0.93-1.92)$ \\
\hline \multicolumn{5}{|l|}{ Allele } \\
\hline $\mathrm{C}$ & $322(68.22)$ & $377(73.63)$ & \multirow[t]{2}{*}{0.061} & 1.00 (reference) \\
\hline G & $150(31.78)$ & $135(26.37)$ & & $1.31(0.99-1.74)$ \\
\hline
\end{tabular}

${ }^{a}$ Genotype frequencies among control subjects did not deviate from the Hardy-Weinberg equilibrium (chi-square $=2.80, \mathrm{P}=0.094) .{ }^{\mathrm{b}}$ Two-sided chi-square test of genotype distributions or allele frequencies in case and control groups. ${ }^{c}$ Obtained from a logistic regression model with adjustments for age, body mass index, cigarette smoking, alcohol drinking, and family history of cancer. $\mathrm{OR}=$ odds ratio, $\mathrm{CI}=$ confidence interval.

\section{Stratified analyses}

Analyses of the association between IL6 genotypes and prostate cancer risk stratified by disease stage (localized: $\mathrm{T}_{1-2} \mathrm{~N}_{0} \mathrm{M}_{0}$; advanced: $\mathrm{T}_{3-4} \mathrm{NxMx}, \mathrm{TxN} \mathrm{N}_{1} \mathrm{Mx}$, or $\mathrm{TxNxM}$ ), pathologic grade (Gleason score $<7,7$, and $>7$ ), and serum PSA level $(\leq 20$ and $>20 \mathrm{ng} / \mathrm{mL}$ ) are shown in Figure 3 and Table S1. The effect of the IL6 polymorphism on prostate cancer risk was found to be significant for localized $(\mathrm{OR}=1.66,95 \% \mathrm{CI}=1.04-2.66, \mathrm{P}=0.034$ for $\mathrm{GC} / \mathrm{GG}$ vs CC) but not advanced disease. The GC/GG genotype was found to be associated with significantly increased risk in subjects with a Gleason score of $7(\mathrm{OR}=1.82,95 \% \mathrm{CI}=1.11$ $3.00, \mathrm{P}=0.019)$. Moreover, increased risk was more pronounced among the subgroup of individuals having never smoked $(\mathrm{OR}=1.85,95 \% \mathrm{CI}=1.07-3.22$; Figure 4 and Table S2 $)$.

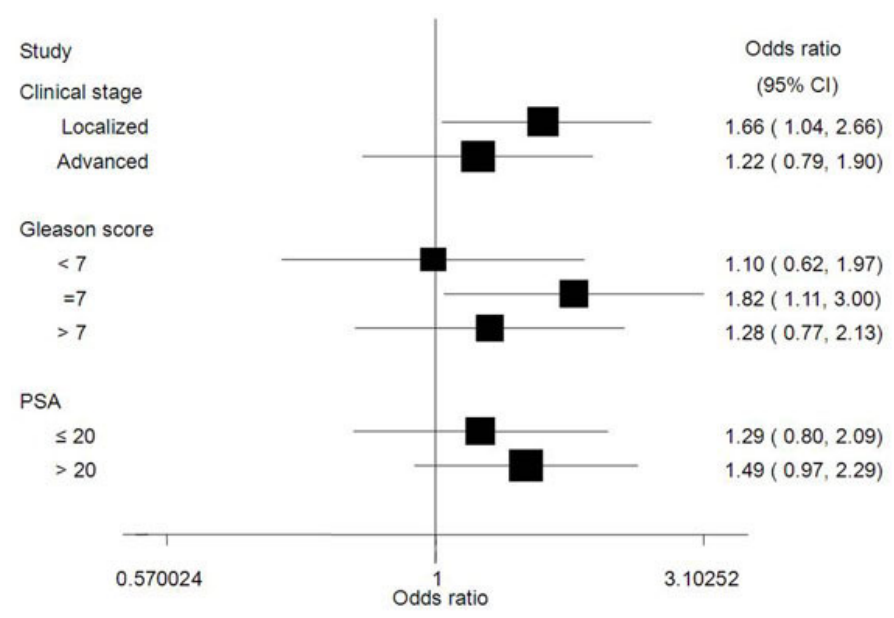

Figure 3. Forest plots representing stratified analyses of the association between the IL6 polymorphism and prostate cancer risk. Odds ratios (ORs) were obtained from a logistic regression model with adjustments for age, body mass index, cigarette smoking, alcohol drinking, and family history of cancer. $\mathrm{CI}=$ confidence interval, PSA $=$ prostate-specific antigen.

Genetics and Molecular Research 15 (3): gmr.15037563 


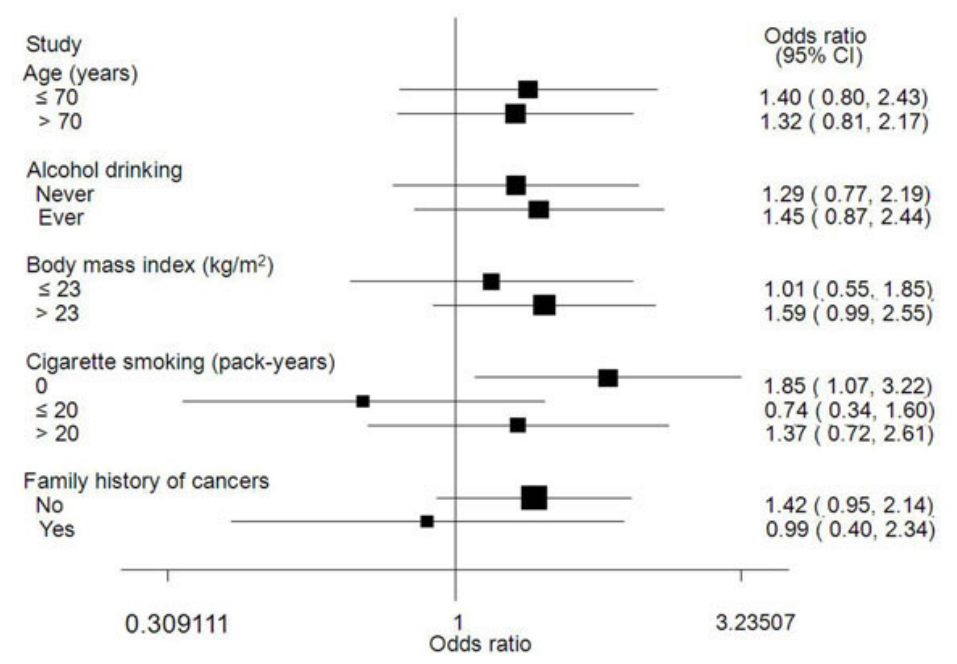

Figure 4. Forest plot of the association between prostate cancer risk and the IL6 polymorphism (GC/CC vs GG) based on stratification of patients by demographic characteristics. $\mathrm{CI}=$ confidence interval.

\section{Dual-luciferase reporter assay}

As shown in Figure 5, the vector carrying the $-572 \mathrm{G}$ allele showed an increase in relative luciferase activity compared with that containing the $-572 \mathrm{C}$ allele, in both DU145 and PC3 cells $(\mathrm{P}<0.001)$.

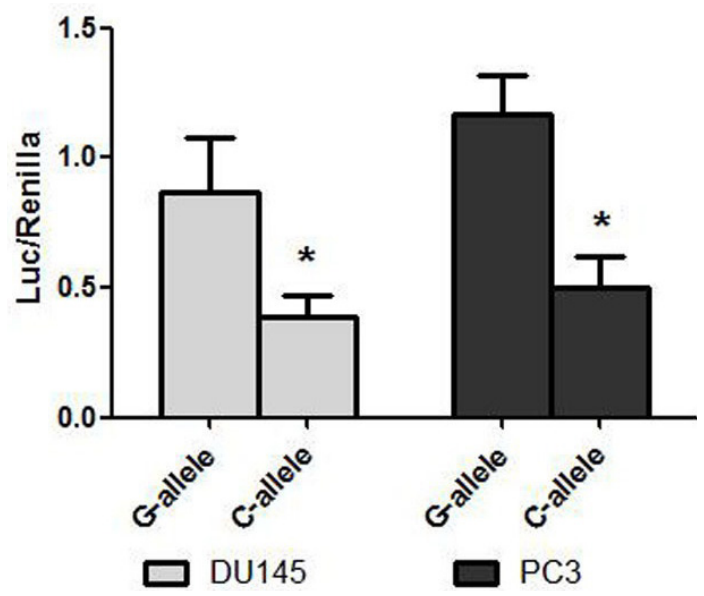

Figure 5. Luciferase reporter assays measuring differences between rs $1800796 \mathrm{G}$ and $\mathrm{C}$ alleles. Cells were transiently transfected with $\mathrm{G}$ or $\mathrm{C}$ allele-bearing reporter vectors. Firefly luciferase activity was measured and normalized to that of Renilla luciferase. Results represent percentages of Renilla luciferase activity. Data are reported as means \pm standard deviations of at least three independent experiments. $* \mathrm{P}<0.05$.

Genetics and Molecular Research 15 (3): gmr.15037563 


\section{DISCUSSION}

In the present study, we focused on prostate cancer risk in relation to the $I L 6-572 \mathrm{G} / \mathrm{C}$ polymorphism. We found this relationship to be significant for never-smokers $(\mathrm{OR}=1.85$, $95 \% \mathrm{CI}=1.07-3.22)$, especially in localized $(\mathrm{OR}=1.66,95 \% \mathrm{CI}=1.04-2.66)$ and moderately differentiated $(\mathrm{OR}=1.82,95 \% \mathrm{CI}=1.11-3.00)$ disease. Furthermore, the $\mathrm{G}$ allele demonstrated increased luciferase activity relative to the $\mathrm{C}$ allele in a dual-luciferase reporter assay. To the best of our knowledge, this is the first study concerning the $I L 6-572 \mathrm{G} / \mathrm{C}$ polymorphism and prostate cancer risk.

This polymorphism appears to be biologically and clinically important. There is increasing evidence that IL6 sequence variations are associated with altered levels of IL6 expression. An association between the $-572 \mathrm{G} / \mathrm{C}$ genotype and increased IL6 concentration has been recently reported in healthy Chinese volunteers (Gu et al., 2008), and in the present study, rs $1800796 \mathrm{G}$ and $\mathrm{C}$ alleles were shown to confer distinct promoter activities during transcription. The association between the $-572 \mathrm{G} / \mathrm{C}$ polymorphism and various diseases has been examined previously, including in duodenal ulcer (Kang et al., 2009), diabetes and periodontitis (Xiao et al., 2009), tuberculosis (Zhang et al., 2012), and hepatitis B virus infection (Zhang et al., 2015). Conflicting conclusions have been reached; however, this is understandable given that IL6 plays various roles in different processes. While revising our manuscript, a paper focusing on the $-572 \mathrm{G} / \mathrm{C}$ polymorphism and prostate cancer risk (Chen et al., 2015) was published supporting our conclusion that this variant contributes to prostate cancer development. However, the present study is more comprehensive and convincing, considering our inclusion of gene-environment interaction analysis and a functional demonstration of this polymorphism's effects.

Stratifying cases by clinical characteristics revealed the GC/GG genotype to be significantly associated with localized, but not advanced prostate cancer. Moreover, significant results were returned in relation to moderately differentiated (Gleason $=7$ ), but not poorly and well-differentiated disease (Gleason $>$ and $<7$ ). Although a correlation has been established between IL6 expression and prostate cancer clinical severity, exactly how the $-572 \mathrm{G} / \mathrm{C}$ polymorphism affects the clinicopathological features of this disease remains unknown. Genetic alterations other than the $-572 \mathrm{G} / \mathrm{C}$ variant may play important roles in the progression and metastasis of prostate cancer, and the numbers of cases in our subgroup analyses were relatively small. Therefore, whether this polymorphism exerts phenotypic effects on prostate cancer deserves further investigation.

As the GC/GG genotype conferred significantly increased risk on never-smokers, it appears that the effect of genotype and its diagnostic value were greater among non-smokers than smokers. Tobacco smoke contains multiple carcinogens, including polycyclic aromatic hydrocarbons and $\mathrm{N}$-nitroso compounds, and smoking has been proven to be an independent risk factor in several cancers (Hecht, 2002). Compared to exposure to these carcinogens, the effect of the $-572 \mathrm{G} / \mathrm{C}$ polymorphism must be relatively weak in smokers. Other risk factors, such as reduced DNA repair capacity among smokers (Wei et al., 2000) might also contribute to this disparity.

\section{CONCLUSIONS}

We demonstrated that the $-572 \mathrm{G} / \mathrm{C}$ polymorphism modulates the transcriptional activity of the IL 6 promoter, resulting in elevated risk of prostate cancer, which was confirmed using data from the Oncomine database.

Genetics and Molecular Research 15 (3): gmr.15037563 


\title{
Conflicts of interest
}

\author{
The authors declare no conflict of interest.
}

\section{REFERENCES}

Cabrespine A, Bay JO, Verrelle P and Morel L (2007). [Interleukin-6 implication in prostate cancer]. Bull. Cancer 94 (Suppl): F29-F34.

Chen CH, Gong M, Yi QT and Guo JH (2015). Role of interleukin-6 gene polymorphisms in the development of prostate cancer. Genet. Mol. Res. 14: 13370-13374. http://dx.doi.org/10.4238/2015.October.26.34

Corcoran NM and Costello AJ (2003). Interleukin-6: minor player or starring role in the development of hormonerefractory prostate cancer? BJU Int. 91: 545-553. http://dx.doi.org/10.1046/j.1464-410X.2003.04025.X

Dennis LK and Dawson DV (2002). Meta-analysis of measures of sexual activity and prostate cancer. Epidemiology 13: 72-79. http://dx.doi.org/10.1097/00001648-200201000-00012

Dennis LK, Lynch CF and Torner JC (2002). Epidemiologic association between prostatitis and prostate cancer. Urology 60: 78-83. http://dx.doi.org/10.1016/S0090-4295(02)01637-0

Gerstenbluth RE, Seftel AD, MacLennan GT, Rao RN, et al. (2002). Distribution of chronic prostatitis in radical prostatectomy specimens with up-regulation of bcl-2 in areas of inflammation. J. Urol. 167: 2267-2270. http://dx.doi. org/10.1016/S0022-5347(05)65140-3

Gu W, Du DY, Huang J, Zhang LY, et al. (2008). Identification of interleukin-6 promoter polymorphisms in the Chinese Han population and their functional significance. Crit. Care Med. 36: 1437-1443. http://dx.doi.org/10.1097/ CCM.0b013e31816a0adb

Hecht SS (2002). Cigarette smoking and lung cancer: chemical mechanisms and approaches to prevention. Lancet Oncol. 3: 461-469. http://dx.doi.org/10.1016/S1470-2045(02)00815-X

Irani J, Goujon JM, Ragni E, Peyrat L, et al.; Pathologist Multi Center Study Group (1999). High-grade inflammation in prostate cancer as a prognostic factor for biochemical recurrence after radical prostatectomy. Urology 54: 467-472. http://dx.doi.org/10.1016/S0090-4295(99)00152-1

Kang JM, Kim N, Lee DH, Park JH, et al. (2009). The effects of genetic polymorphisms of $I L-6, I L-8$, and $I L-10$ on Helicobacter pylori-induced gastroduodenal diseases in Korea. J. Clin. Gastroenterol. 43: 420-428. http://dx.doi. org/10.1097/MCG.0b013e318178d1d3

Lee TH, Sakahara NS, Fiebig EW, Hirschkorn DF, et al. (1998). Quantitation of white cell subpopulations by polymerase chain reaction using frozen whole-blood samples. Viral Activation Transfusion Study. Transfusion 38: 262-270. http://dx.doi.org/10.1046/j.1537-2995.1998.38398222870.x

Platz EA and De Marzo AM (2004). Epidemiology of inflammation and prostate cancer. J. Urol. 171: S36-S40. http:// dx.doi.org/10.1097/01.ju.0000108131.43160.77

Schatteman PH, Hoekx L, Wyndaele JJ, Jeuris W, et al. (2000). Inflammation in prostate biopsies of men without prostatic malignancy or clinical prostatitis: correlation with total serum PSA and PSA density. Eur. Urol. 37: 404-412. http:// dx.doi.org/10.1159/000020161

Sun J, Turner A, Xu J, Grönberg H, et al. (2007). Genetic variability in inflammation pathways and prostate cancer risk. Urol. Oncol. 25: 250-259. http://dx.doi.org/10.1016/j.urolonc.2006.10.001

Terry CF, Loukaci V and Green FR (2000). Cooperative influence of genetic polymorphisms on interleukin 6 transcriptional regulation. J. Biol. Chem. 275: 18138-18144. http://dx.doi.org/10.1074/jbc.M000379200

Wei Q, Cheng L, Amos CI, Wang LE, et al. (2000). Repair of tobacco carcinogen-induced DNA adducts and lung cancer risk: a molecular epidemiologic study. J. Natl. Cancer Inst. 92: 1764-1772. http://dx.doi.org/10.1093/jnci/92.21.1764

Xiao LM, Yan YX, Xie CJ, Fan WH, et al. (2009). Association among interleukin-6 gene polymorphism, diabetes and periodontitis in a Chinese population. Oral Dis. 15: 547-553. http://dx.doi.org/10.1111/j.1601-0825.2009.01584.x

Zhang G, Zhou B, Wang W, Zhang M, et al. (2012). A functional single-nucleotide polymorphism in the promoter of the gene encoding interleukin 6 is associated with susceptibility to tuberculosis. J. Infect. Dis. 205: 1697-1704. http:// dx.doi.org/10.1093/infdis/jis266

Zhang G, Wang W, Li S, Yang H, et al. (2015). IL6 gene allele-specific C/EBPa-binding activity affects the development of HBV infection through modulation of Th17/Treg balance. Genes Immun. 16: 528-535. http://dx.doi.org/10.1038/ gene. 2015.40

\section{Supplementary material}

Table S1. rs1800796 and clinicopathological characteristics in patients with prostate cancer.

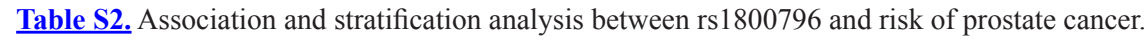

Genetics and Molecular Research 15 (3): gmr.15037563 